\title{
Canine Scabies: A Zoonotic Ectoparasitic Skin Disease
}

\author{
R.P. Diwakar* and R.K. Diwakar \\ Department of Veterinary Microbiology, C.V.Sc and A.H., Kumarganj, \\ Faizabad (U.P)-224229, India \\ *Corresponding author
}

A B S T R A C T

Keywords

Canine scabies,

Zoonotic disease,

Sarcoptes scabiei canis, Ectoparasite.

Article Info

Accepted:

12 March 2017

Available Online:

10 April 2017
Mange is a class of skin diseases caused by parasitic mites. Sarcoptic mange is one of the common contagious skin diseases affecting all the domestic animals through host- adapted variants. All the dogs had intense itching, restlessness, frantic scrating hair-loss, red skin all over the body and scabs. Distribution of the lesions was noticed at the margins of the ears, elbows, face and legs. Parasitic mites that cause mange in mammals embed themselves either in skin or hair follicles in the animal, depending upon their genus. Sarcoptes spp. burrows into skin, while Demodex spp. live in follicles

\section{Introduction}

Sarcoptic mange, also known as canine scabies, is a highly contagious infestation of Sarcoptes scabiei canis, a burrowing mite. The canine sarcoptic mite can also infest cats, pigs, horses, sheep, and various other species. The human analog of burrowing mite infection, due to a closely related species, is called scabies (the "seven year itch").

All these burrowing mites are in the family Sarcoptidae. They dig into and through the skin, causing intense itching from an allergic reaction to the mite, and crusting that can quickly become infected. Hair loss and crusting frequently appear first on elbows and ears. Skin damage can occur from the dog's intense scratching and biting. Secondary skin infection is also common. Scabies is a skin disease of all types of domestic's animals including dog and cat as well as it is zoonotic in nature.

Canine scabies is of public health importance as $50 \%$ of human cases may result from handling of infected dogs. Human patients usually recover spontaneously after infected dog are cured. Foxes can also be an important vector of $S$. scabiei in geographically areas where a large population infected foxes exit, such as in Sweden. Therefore foxes may serve as reservoirs for $S$. scabiei infection. 


\section{Incidence}

The prevalence of Sarcoptes scabiei infestation in dog varies according to the Age, Breed, Sex, Hair coat etc. Various workers have reported varying extents of prevalence of scabies in dog as $68 \%$ in less than 5 month of age, 35.71 and $26.19 \%$ in less than 6 month and 7-12 month of age respectively. The mite affects higher percentage of female (39.3\%) than males (35.2\%) (DIMRI.1988)

\section{Appearance of the disease}

The motion of the mite in and on the skin is extremely itchy. Furthermore, burrowed mites and their eggs generate a massive allergic response in the skin that is even itchier.

\section{Life cycle of causative agent}

The mites usually spend their entire life on a dog. The female mite burrows into the skin and lays eggs several times as she continues burrowing. These tunnels can actually reach the length of several centimeters. After she deposits the eggs, the female mite dies. In 3-8 days, the eggs hatch into larvae which have 6 legs.

The larvae mature into nymphs which have 8 legs. The nymph then molts into an adult while it is still in the burrow. The adults mate, and the process continues. The entire life cycle requires 2-3 weeks.

The mites prefer to live on the dog, but will live for several days off of the host in the environment. In cool moist environments, they can live for up to 22 days. At normal room temperature in a home, they will live from 2 to 6 days. Because of the mite's ability to survive off the host, dogs can become infected without ever coming into direct contact with an infected animal.

\section{Pathogenesis}

The causative mite has a lifecycle of 17 to 21 days. Copulation of adults occurs on the skin. The fertilized female live in burrow in the horney layer of the skin and lays egg.

The egg hatch two larvae, which develop into nymph in burrows mites prefer skin with little hair so they are most common on the ears, elbows, abdomen, hocks. Adult mites are small (200-400 mm), oval and with two pairs of anterior and two pairs of posterior legs. Scabies is highly contagious and it spread readily by direct contact. Animal of all legs, sexes and breed are equally susceptible but artificial age bias may exist for susceptibility of younger dog due to habitat situations

\section{Clinical features}

In canine scabies the lesions are typically found on the ventral portion of the abdomen, chest and legs. The ears and elbows, favourite habitat of mite are almost always affected. The diseases rapidly until the entire body may be affected. The affected dogs exhibit severe itching, inflammation, erythema of skin and even crust formation and creatinization. Canine scabies progressed with initial encrustation on the ischium four and hind leg to severe thickened state - Grey hyperkeratotic lesion with almost complete alopecia.

Haematological picyure in affected dog indicate lower erythrocytes count, packed cell volume, haemoglobin (Dimri, 1988) and increased totle leukocyte count (TLC) with neutrophilia (Chandy et al., 2000).

\section{Zoonotic importance}

Scabies is most common among people who live in overcrowded conditions, and whose ability to practice good hygiene is limited. 
Scabies can be passed between people by close skin contact. Although the mites can only live away from human skin for about three days, sharing clothing or bedclothes can pass scabies among family members or close contacts. In May 2002, the Centers for Disease Control (CDC) included scabies in its updated guidelines for the treatment of sexually transmitted diseases.

Mite burrows within the skin are seen as winding, slightly raised gray lines along a person's skin. The female mite may be found at one end of the burrow, as a tiny pearl-like bump underneath the skin. Because of the intense itching, burrows may be obscured by scratch marks left by the patient.

The most common locations for burrows include the sides of the fingers, between the fingers, the top of the wrists, around the elbows and armpits, around the nipples of the breasts in women, in the genitalia of men, around the waist (beltline), and on the lower part of the buttocks. Babies may have burrows on the soles of their feet, palms of their hands, and faces.

The itching from scabies becomes worse after a hot shower and at night. Scratching, however, seems to serve some purpose in scabies, as the mites are apparently often inadvertently removed. Most infestations with scabies are caused by no more than 15 mites altogether.

Infestation with huge numbers of mites (on the order of thousands to millions) occurs when an individual does not scratch, or when an individual has a weakened immune system. These patients include those who live in institutions; are mentally retarded, or physically infirm; have other diseases which affect the amount of sensation they have in their skin (leprosy or syringomyelia); have leukemia or diabetes; are taking medications that lower their immune response (cancer chemotherapy, drugs given after organ transplantation); or have other diseases which lower their immune response (such as acquired immunodeficiency syndrome or AIDS ).

This form of scabies, with its major infestation, is referred to as crusted scabies or Norwegian scabies. Infected patients have thickened crusty areas all over their bodies, including over the scalp. Their skin appears scaly, and their fingernails may be thickened and horny.

\section{Diagnosis}

Sarcoptic mites are difficult to find, and therefore multiple deep. Scrapings are indicated. Skin sites that have not been excoriated are preferred for scrapings. One mite or its dark brown oval fecal pellets are diagnostic. One of the best diagnostic aids is the prompt response to therapy.

Other diagnostic aids such as enzyme -linked immunosorbent assay (ELISA) for the serological diagnosis of canine sarcoptic mange has been evaluated but is not of much importance for Indian field conditions. Many clinicians rub the dog's ears flap on itself, in case with lesions the hind leg scratches reflex will be stimulated. This is a sign suggestive of sarcoptic mange (Muller, 2001). Histopathology reveals acanthosis, parakeratosis, epidermal necrosis and infiltration of neutrophils and eosinophils (Chandy, 2000).

Differential diagnosis should include contact dermatitis, atopy flea or food allergy, pelodera dermatitis, pediculosis, cheyletiellosis, otodectic dermatitis, dermatophytosis, seborrheic dermatitis, generalized pyoderma or folliculitis and bacterial hypersensitivity. 
Fig.1 A and B showing canine scabies: skin disease

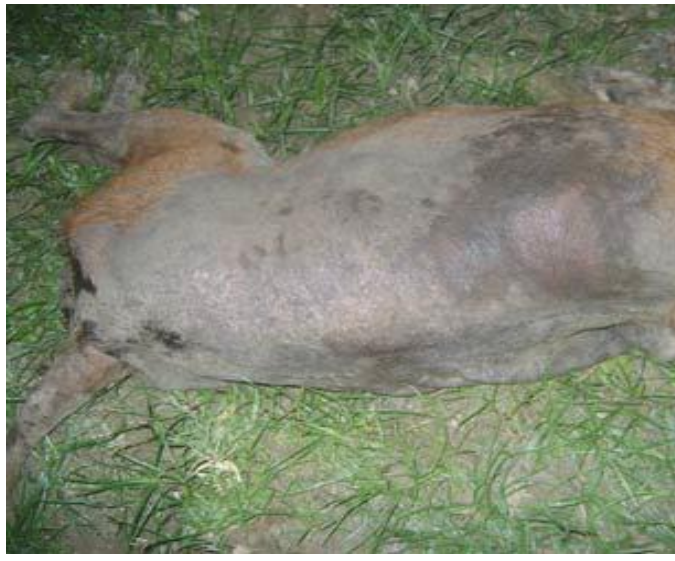

\section{Treatment}

Treatment should be started as early as the diagnosis is made. Hairs should always be clipped and the patient bathed with an antiseborrheic shampoo to remove crust and other debries. Thereafter acaricidal dip should be given thoroughly. Pruritus is an unpleasant sensation, which provokes the desire to scratch and may be peripheral or central in origin. The major mediator of pruitus in dogs is thought to be, proteolytic enzymes and biochemical mediators like histamine which play major role on producing this symptom. To provide relief from pruritus and to stop self mutilation systemic cortcosteroids many be administered in their usual-inflammatory doses i.e. Prednisone or Prednisolone @ 0.5 to $1.0 \mathrm{mg} / \mathrm{kg}$ body weight orally daily for $2-5$ days.

Amitraz has been an effective miticide if used three time at 2 week interval (folz). Synthetic pyrethroidsa like deltamethrin have also been found very defective in treating the cases of canine scabies in 1:250 and 1:500 dilutions twice at 10 day interval (Sharma, 1991) Ivermectin and its related drugs are found quite effective in scabies. Single subcutaneous injection of 200 to 400 micro gram ivermectin (Singh and Gill, 1987; Yazwinski et al., 1981) and selamectin

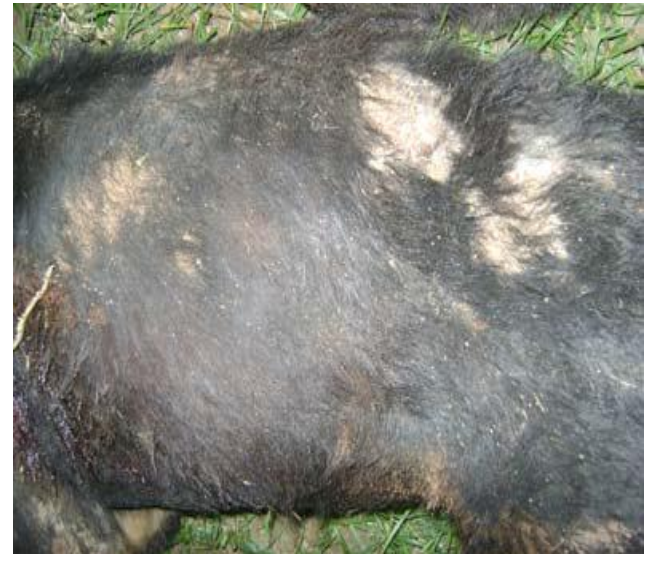

$@ 6 \mathrm{mg} / \mathrm{kg}$ in a topical preparation as a unit dose was reported to cure scabies (Six et al., 2000). Ivermectin should never be used in 0.25 per cent spray to cure scabies (Curtis, 1996). Commercial lime-sulfur orchard spray solution is especially safe and effective. It has no residual effect but is miticidal, antifungual and antipruritic. The lime sulfur should be applied warm as 2 to $3 \%$ solution after a cleansing bathed and repeated weekly at least four times. Therapy should not be stopped too early, because it may take months for a complete response to occur. Treatment is not completed until the last egg has hatched and last mite has been killed.

Other drugs like milbemycin oxime @2 $\mathrm{mg} / \mathrm{kg}$ weight in 2 or 3 does is also an effective scabicidal (Miller et al., 1996). A number of herbal compound have been tried and it has been found that extract of Cedrus deodara and Pangamia glabra is quite effective against canine scabies (Das, 1996) experimentally infested dogs expressed successful adaptive immunity and cured themselves of Sarcoptes scabiei var canis infection after previously having scabies that required treatment to cure (Stemmer et al., 1996).

It is important to treat all animal or the premises as some may be asymptomatic 
carrier of scabies the mites are easily killed by drying when they are off the host a few days parasiticidal spray should be used on kennels, shipping boxes, harnesses, collars and brushes to clean the environment.

\section{References}

Chandy Juney Nambi, A.P., Jeyaraja, K. and Gowari, B. 2000. Clinico pathological and biochemical studies in scabies in dog, Indian Vet. J., 77: 755-757.

Das, S.S. 1996. Effect of a herbal compound for treatment of sarcoptic mange infestation on dogs. Vet. Parasitol., 63: 303-306.

Dimari, U. 1998. Clinico therepeutic studies on skin diseases in dogs, sheep and goats. Ph.d thesis submitted to deemed university, Indian Veterinary Research Institute, Izatnagar, India.

Folz, S.D., Kratzer, D.D., Kakuk, J.J. and Rector, D.L. 1984. Evaluation of a sponge on therapy for canine scabies. J. Vet. Pharamacol. Ther., 7: 29.

Millerjr, W.H., Jaham, C., Scott, D.W. Cayatte, S.M., Bagladi, M.S. and Buerger, R.G. 1996. Treatment of canine scabies with millbemycin oxime. Can. Vet. J., 37: 219-221.

Muller, R.S., Bettenag, S.V. and Shipstone, M. 2001. Value of pinnae-pedal reflex in the diagnosis of canine scabies.Vet.
Rec., 148: 621-623.

Sharma, M.C., Swarup. D. and Lal, S.B. 1991. Therapeutic efficacy of butox against mange in dogs. Indian Vet. J., 68: 80-83.

Singh, J., and Gill, B.S. 1987. Ivermectin treatment of sarcoptic mange in dogs. Mod. Vet. Pract., 68: 437.

Six, R.H., Clemence, R.G., Thomas, C.A., Behan, S., Boy, M.G., Watsan, P., Benchaoui, H.A., Clements, P.J.M., Rowan, T.G. and Jernigan, A.D. 2000. efficacy and safety of selamectin against sarcoptes scabiei on dogs and otodectes cynotis on dogs and cats presented as veterinary paients. Vet. Parasitol., 91: 291-309.

Stemmer, B.L., Arlian, L.G., Morgan, M.S., Rapp, C.M. and Moore, P.F. 1996. Characterization of antigen presenting cell and T-cells in progressing scabietic skin lesion. Vet. Parasitol., 67: 247-258.

Yazwinski, T.A., Pote, L., Tilly, W., Rodriguez, C. and Greenway, T. 1981. Efficacy of ivermectin against Sarcopties scabies and Otodectes cynotis infection of dog, Vet. Med., (SAC).

Curtis, C.F. 1996. Use of 0.25 percent fipronil spary to treat sarcoptic mange in a litter of five week old puppies. Vet. Record, 139: 43-44.

\section{How to cite this article:}

Diwakar, R.P. and Diwakar, R.K. 2017. Canine Scabies: A Zoonotic Ectoparasitic Skin Disease. Int.J.Curr.Microbiol.App.Sci. 6(4): 1361-1365. doi: https://doi.org/10.20546/ijcmas.2017.604.165 